\title{
SPECIAL REPORT
}

\section{The methane mystery}

The claim that living plants emit the greenhouse gas methane has shaken up atmospheric scientists. Quirin Schiermeier talks to the experts trying to make sense of the measurements.

t t took 18 years, but Paul Crutzen and Eugenio Sanhueza finally found a use for their data. In 1988, the two atmospheric chemists had discovered large amounts of the greenhouse gas methane building up at night over Venezuela. This March, they dusted off their data and used them to calculate a surprising number: that the world's tropical savannahs may produce 30 million to 60 million tonnes of methane each year ${ }^{1}$.

Remarkably, that number is similar to one reported in January, when a German chemist announced that living plants give off meth$a^{2} e^{2}$. His claim rattled many, because textbooks hold that methane is produced from organic matter decaying in oxygen-free environments, not from living plants. If true, his finding could account for a substantial fraction of the methane entering the atmosphere - potentially throwing off calculations of how much humans contribute.

In the past seven months, atmospheric scientists have scrutinized the discovery, and they're finding that methane does not yield up its secrets easily. Some, like Crutzen, find the work convincing. "We could have seen the effect a long time ago, but we missed the boat,"

\section{Missing mechanism}

How plants might produce methane remains a mystery.

Frank Keppler, the chemist who proposed the idea in January, ruled out the possibility that the gas could have come from bacteria in leaves, or enzymes in plant cells. This suggests that plants somehow produce the methane 'autonomously', without a protein to catalyse the reaction.

Instead, Keppler proposed a chemical pathway involving pectin. These molecules, a mix of different sugars used by plant cells, are constantly being synthesized and degraded - a process that could produce methane. But how that would work is the subject of much debate.

Other chemical reactions that could release methane would require the presence of unstable carbohydrate molecules in the plant cells, says botanist Jürgen Kesselmeier of the Max Planck Institute of Chemistry in Mainz, Germany. Plant physiologists don't yet know what those might be. says Crutzen, who works at the Max Planck Institute (MPI) for Chemistry in Mainz, Germany, and shared the 1995 Nobel Prize in Chemistry for his work on atmospheric ozone. Sanhueza works at the Venezuelan Institute for Scientific Investigations in Caracas.

Others are not swayed. "I am not yet convinced that the effect is real," says David Beerling, a palaeoclimatologist at the University of Sheffield, UK. "The experiments leave a lot of questions open, and the findings still await independent verification."

And some just aren't sure. "The new source is very hard to distinguish from known methane sources such as wetlands, and the scarce existing data can neither prove nor disprove its existence," says Martin Heimann, an atmospheric chemist at the MPI for Biogeochemistry in Jena, Germany.

\section{Time to adjust}

The debate began with the work of Frank Keppler, a geochemist at the MPI for Nuclear Physics in Heidelberg, Germany, and his colleagues. The researchers grew various plants in isolated chambers, then measured the background methane concentrations. The fluxes were tiny; but when extrapolated to global vegetation they pointed to the existence of a huge, overlooked source of methane. Plants, it seemed, could account for up to $40 \%$ of total methane emissions (see 'Missing mechanism').

As a greenhouse gas, methane traps heat 20 times more efficiently than carbon dioxide, yet its sources and sinks are less well understood. Total methane emissions are estimated to be around 550 million tonnes per year. The known sources include wetlands, rice farming, the stomachs of ruminant animals, biomass burning, landfills and energy generation. And now, perhaps, plants.

If Keppler is right, rapid tropical deforestation could explain why atmospheric methane concentrations stopped rising in the 1980s, after decades of increase. Looking further back in time, the effect could have played a role in the transition from glacial periods to warmer climates, says Thomas Röckmann, an atmosphere researcher at the Utrecht University in the Netherlands. Warmer temperatures could mean more plants, which in turn produce more heat-trapping methane.

But most researchers are cautious about

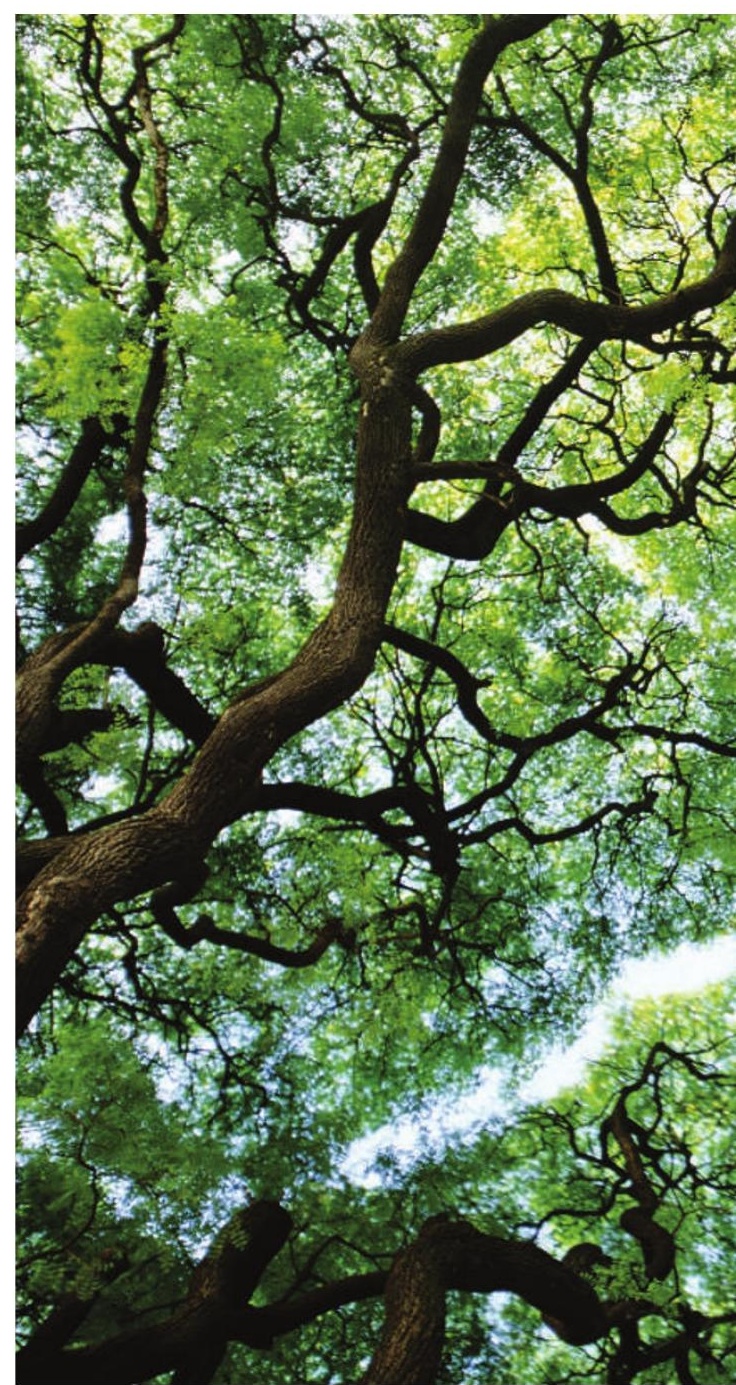

jumping to conclusions, particularly in extrapolating Keppler's laboratory observations to global values. Keppler calculated a global source in the range of 62 million-236 million tonnes per year. Other ways of scaling up his data suggest the source might be substantially smaller.

For instance, critics say Keppler overestimated the amount of methane-producing plant tissue by basing his calculations on global 'net primary production' of vegetation, which includes roots and stems, rather than global leaf mass only. When climate modeller Miko Kirschbaum of the Cooperative Research Center for Greenhouse Accounting at the Australian National University in Canberra adjusted the calculation accordingly, he arrived at global emissions of only 10 million- 60 million tonnes per year ${ }^{3}$.

Others have looked at the carbon-isotope ratios of methane in ice cores. Different sources of methane yield different isotope signatures. A 2,000-year ice-core record from 


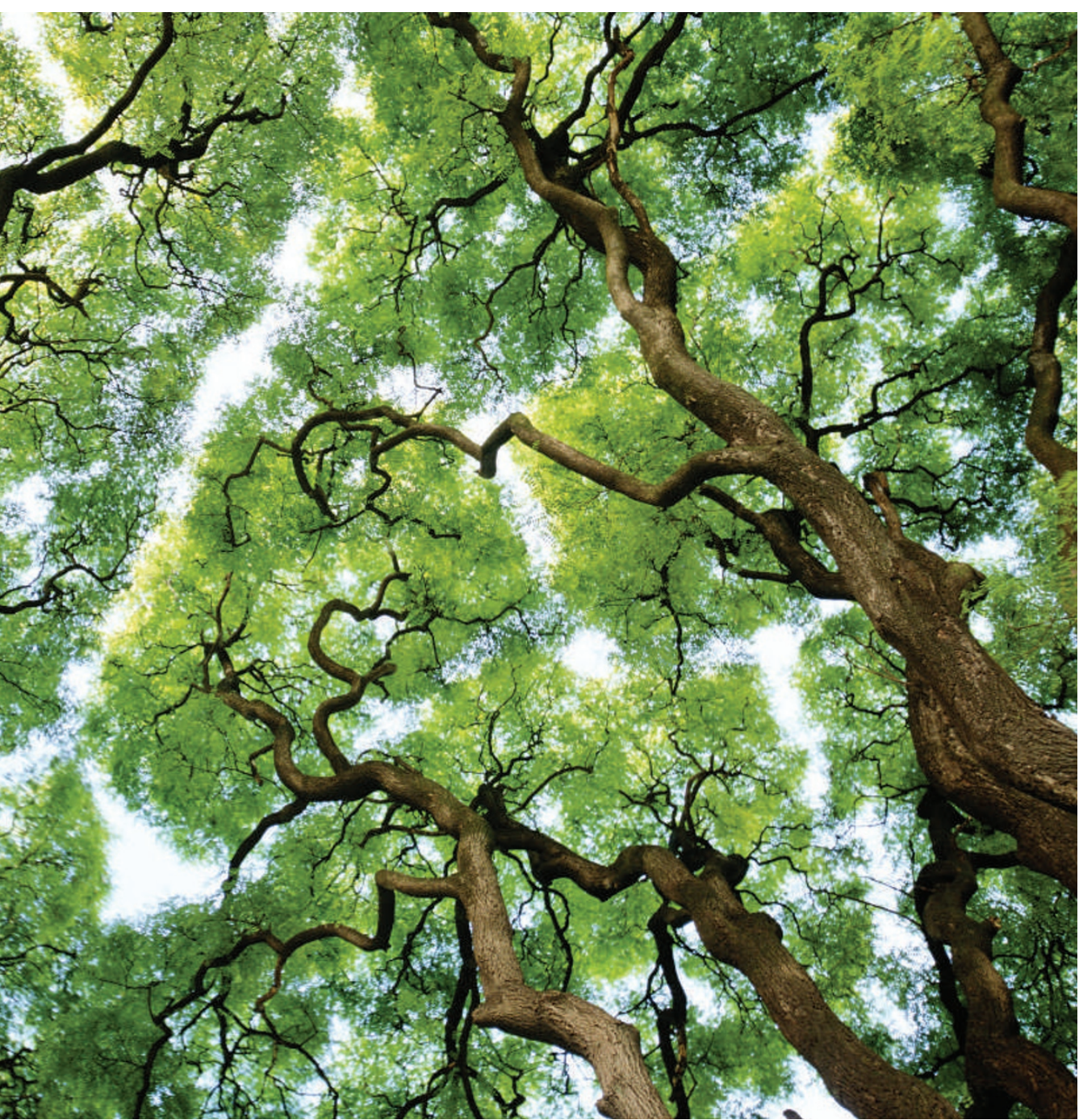

Green greenhouse? If plants produce a lot of methane, it could affect political efforts to cut emissions.

Antarctica yielded an upper limit of 46 million tonnes per year".

But not everyone is revising Keppler's findings downward. One new simulation, of how methane moves through the atmosphere, suggests that plants yield on the order of 125 million tonnes per year. Sander Houweling, of Utrecht University, simulated methane fluxes both with and without methane emissions from plants. He found that the results better match observations if vegetation is included
"Unpublished data show that some plant species emit up to 4,000 times more methane than others."
And he promises further surprises. Unpublished data from experiments carried out last year in Brazil, on five randomly selected plant species, show that some species emit up to 4,000 times more methane than others. If this is true, it will make it even more difficult to calculate the size of the global source, he says.

If plants are giving off more methane than was thought, then another source of methane must have been overestimated. Most scientists suspect that this is wetlands. More unlikely, but politically more contentious, is as a source of methane ${ }^{5}$.

Keppler, a co-author of this study, says he can "live very well" with attempts to re-interpret and downscale his findings. The 39-year-old researcher recently received a European Young Investigator Award, allowing him to continue work in the area for at least five more years. the possibility that one or more of the humanrelated sources might be much smaller than was thought, says Johannes Lelieveld, a director of the MPI for Chemistry.

The German gas company Ruhrgas has already asked Lelieveld whether it can revise downward its estimates of how much methane its power plants have emitted. “That's probably $\sum_{\Sigma}^{+}$ going too far," says Lelieveld. "But a major discovery like this does require reassessment of greenhouse-gas sources."

As usual, more data would help. "The ultimate test is to do more and better measurements," says Ed Dlugokencky, an atmospheric chemist with the US National Oceanic and Atmospheric Administration in Boulder, Colorado, who oversees the methane part of a global air-sampling network.

Dlugokencky is convinced that the effect is real. "I'm not surprised we missed it," he says. "Our network of 60 stations is just too small to be able to detect it, and we are particularly weak in the tropics where it seems to be most pronounced."

\section{In flux}

Another way to hunt methane could be from space. As reported last year, the European Envisat satellite has detected large plumes of methane over tropical rainforests ${ }^{6}$. But remote sensing cannot prove that the gas stems from trees, as opposed to swamps, bogs or wetlands underneath.

"You can learn a lot from space," say Crutzen. "But to verify sources you need to go back to places such as Venezuela and Brazil and look at methane in situ."

Eddy-flux towers, which are already being used at more than 200 sites worldwide to measure the movement of carbon dioxide in and out of the atmosphere, might help. Methane is less abundant than carbon dioxide, and so harder to monitor. But new and more powerful lasers will measure gas concentrations more accurately. Soon, says Heimann, it may be possible to measure methane fluxes above tree canopies in real time - perhaps even tracing them back to individual plants.

Such information should improve estimates of the global methane budget. With that, researchers hope to move closer to their ultimate goal: developing a computer model that accurately reproduces past climate and all its biospheric feedbacks.

A model of the past should also provide projections for the future. "You need to understand the entire greenhouse budget," says Dlugokencky, "before you can start thinking about mitigating climate change."

\footnotetext{
. Crutzen, P. J., Sanhueza, E. \& Brenninkmeijer, C. A. M. Atmos. Chem. Phys. Disc. 6, 3093-3097 (2006).

2. Keppler, F. et al. Nature 439, 187-191 (2006)

3. Kirschbaum, M. U. F. et al. Funct. Plant Biol. 33, 521-530 (2006).

4. Ferretti, D. F. et al. Atmos. Chem. Phys. Disc. 6, 5867-5875 (2006).

5. Houweling, S. et al. Geophys. Res. Lett. (in the press). 6. Frankenberg, C. et al. Science 308, 1010-1014 (2005).
} 